Bethan L. Davies*

\title{
Evaluating evaluations: What different types of metapragmatic behaviour can tell us about participants' understandings of the moral order
}

https://doi.org/10.1515/pr-2017-0037

Abstract: Participant evaluations have been at the heart of recent discursive (im)politeness research, yet despite their importance, there has been little consideration of how we identify such behaviours and how we can substantiate their worth in an analysis. In this paper, it is proposed that we need to distinguish between different, ordered, categories of evaluation because these provide different levels of evidence for participants' understandings of (im)politeness.

Using online comments from Daily Mail articles relating to the Penelope Soto court hearings, I show that apparent agreements in the classification of linguistic behaviour as (im)polite can mask disagreements in the underlying rationales for those judgements. It is these rationales that provide the strongest warrant for analysts because they represent the ideological basis behind an individual's understanding of politeness - why people should behave in this way. This links to Haugh's (2013) use of 'moral order' and also Eelen's (2001) key, but underdeveloped, notion of argumentativity. The rationale behind an individual's judgement provides the argumentative link between metapragmatic behaviour and the social order. Classifications and positive/negative assessments of person are only clues to this underlying rationale, and need to be treated as such. Understanding these differences will assist analysts in assessing the ideological weight of metapragmatic behaviour and provide better-informed warrants for their analyses.

Keywords: Evaluation, argumentativity, moral order, second order politeness, metadiscourse

*Corresponding author: Bethan L. Davies, School of Languages, Cultures and Societies, University of Leeds, Leeds, United Kingdom, E-mail: B.L.Davies@leeds.ac.uk 


\section{Introduction}

This article uses data from the comments section of online reportage to investigate the nature of metapragmatic behaviour and how it can be theorized more effectively. Following Haugh (2013), it is argued that the enthusiasm for the concept of evaluation in discursive approaches to (im)politeness has overtaken the degree to which it has been theorized. This article is an attempt to address that balance. It offers a more nuanced way of thinking about evaluation by identifying different types of evaluative behaviour and thus providing a robust method of discriminating between the warrants that they can offer an analysis. In turn, this approach also makes a contribution to the debate about the position of metapragmatic comment within first and second order politeness (Eelen 2001; Kádár and Haugh 2013) as it demonstrates both how a lay theoretical position would be constituted and how it could be identified.

Like the other papers in this special issue, the focus of attention is a Florida courtroom bail hearing involving Penelope Soto and Judge Rodriguez-Chomat where Soto swore and used a rude hand gesture. ${ }^{1}$ However, rather than examining their talk-in-interaction, this research looks at online newspaper reportage of the event and the user-generated comments that responded to it. Video footage of this event went viral in February 2013. The story was picked up by the media in both the USA and the UK, leading to a flurry of discussion about Soto's behaviour, often centering on issues related to what could broadly be termed (im)politeness. The particular stories chosen were published by the online arm of the UK newspaper, The Daily Mail, and related to Soto's bail hearing and two further interactions with the USA court system. The point of focusing on these metapragmatic comments is to identify what features of Soto's behaviour prompted (im)politeness comments and how these were then related to societal views of (im)politeness. The intention is to provide an interesting counterpoint to the analyses of the courtroom interaction itself alongside a more thorough exploration of evaluation as a tool for analysis.

The starting point for this research is the position that evaluation is not an homogeneous category. It is argued that three different levels of evaluative behaviour can be distinguished - moving from classifications of (im)politeness, to assessments of person, to rationales underlying these judgements. These warrant different things within an (im)politeness analysis, and recognizing this

1 A YouTube video of the interaction can be accessed here: https://www.youtube.com/ watch?v=MbJTUrM0JsI. There is also a link via the original Daily Mail article (Reilly 2013a) and links to the following court interactions can be accessed via the remaining two Daily Mail articles (Reilly 2013b; Daily Mail Reporter 2013). 
will make our analyses more robust. A simple classification of some linguistic behaviour as 'polite', 'impolite' or 'rude' does not, in itself, tell us why that judgment has been made, for example. It is the rationale underlying these classifications that offers insights into that ideological function.

The idea of 'rationale' ties in with Eelen's (2001) concept of argumentativity - which for him was an integral part of evaluation. However, this concept has received little attention in recent years despite the focus on evaluation within (im)politeness research. This may be because argumentativity was described in somewhat abstract terms rather than in a way that could be applied straightforwardly in an analytical setting. This is a deficit in current models of evaluation given that Eelen posits argumentativity as the link between metapragmatic behaviour and the mechanisms through which societal structures can be invoked and thus reinforced; it is the potential link between metapragmatic behaviour and a conception of the 'moral order' (Garfinkel 1967; Haugh 2013; Kádár and Haugh 2013). The model of evaluation offered here addresses this issue by elaborating the concept of argumentativity and demonstrating how it can be operationalized as one type of evaluation, rationale, and clearly differentiated from two others: classification and assessment. This puts argumentativity back in its rightful place as an intrinsic part of evaluation, whilst still allowing it to be distinguished from other kinds of metapragmatic behaviour.

Discriminating between different levels of evaluation in this way also has a further benefit in terms of our theoretical understanding of the relationship between metapragmatic behaviour and the different orders of (im)politeness. Kádár and Haugh (2013) argue that there needs to be an acknowledgement of the existence of lay theorizing about (im)politeness (i.e., second order metapragmatic behaviour), however, they do not say how we should recognize such behaviour. It is argued here that it can be located in the argumentative link between classification/assessment behaviour and the posited moral order: what we have termed the rationale.

In order to locate the data analysis, the first sections of this paper discuss the notions of evaluation and argumentativity in detail before presenting a model of evaluation that identifies and distinguishes the three different levels introduced briefly above. The importance of discriminating these levels, and the additional understanding it can offer, is then demonstrated through analyzing the corpus of user-generated comments to online news reportage relating to the Penelope Soto case. 


\section{Evaluation and metapragmatic behaviour}

Haugh (2013) has argued that the term 'evaluation' has been used rather loosely in (im)politeness research since the discursive shift in the early 2000s brought the concept to prominence. There was a shift away from analyst-centered theoretical approaches to a reliance on the identification of 'evaluative moments' in talk as a way of validating assessments of (im)polite behaviours. However, the process of the identification and interpretation of these moments has been left rather 'under-theorised' (Haugh 2013: 53), meaning there is no agreed way to determine the strength of these analyses. In this paper, I will argue that there are different components that make up the process of evaluation and that, by identifying these and their different ideological effects, we can make stronger claims about the inferences based on evaluations. In order to achieve this, I will use Eelen's (2001) notion of argumentativity as a bridge between the evaluative moment and what Kádár and Haugh (2013) term the 'moral order': the taken-for-granted assumptions of 'proper' behaviour that underlie any claim to evaluate another.

The particular data focused on here is well-fitted to this task because it provides an interesting intersection of participant types, metapragmatic comment and first order/second order (im)politeness. One of the first issues with the concept of evaluation is that only limited attention has been paid to the potential differences between the metapragmatic behaviour of those engaged in an interaction as compared to that of lay observers. The 'discursive shift' involved a shift away from an omniscient expert but it did not discuss the role of different types (and degrees) of lay involvement. Kádár and Haugh (2013) set out ways in which we might start to think about various types of participants in these diverse contexts, and the extended types of participation that are now more readily available in our mediated world. However, they have not applied this to a data set or investigated how a particular configuration of participation might affect the type and ideological impact of metapragmatic behaviour.

As research which is grounded in evaluations, the work reported here could be considered what Grainger (2013) and Culpeper (2011) have termed 'second wave' politeness research. Certainly, it is centered around metadiscursive reactions to talk events but, unlike the kind of metapragmatic behaviour assumed in work such as Eelen (2001) or Locher and Watts (2005), these are not the judgements of those who are (or have been) directly engaged in a particular interaction. They are cultural insiders in terms of the emic/etic distinction (or at least position themselves as such) but they are not insiders to the emergent process of this particular piece of talk. As such, they cannot offer the kind of insider insights that the initial discursive shift in politeness research is predi- 
cated upon - while they might comment on the process of talk, they are not strictly ratified participants (Goffman 1981). This does not invalidate the worth of their metapragmatic behaviour as an analytical resource but it does require awareness of this difference, particularly in relation to their different purposes in engaging in it.

Kádár and Haugh (2013) discuss this issue in relation to the limitations of Goffman's participation framework for a mediated age. They make the point that more complex understandings of participant roles are needed within our digital and mediated world - overhearing audiences are a pivotal and expectable component of both traditional and online media. Indeed, Dynel (2011) argues that film audiences (and by extrapolation, TV and radio) should be considered ratified because there are features of recipient design that are managed specifically for them. The situation is even more complex for the case here. The original video data, which forms the basis for most of the articles in this special issue, has not been manipulated or managed for an audience but is publically available - thus making it subject to unratified overhearing. However, once the video has been embedded into online newspaper reportage and has been subject to the mediatization process of being reformulated as reportage with news values (Harcup and O'Neill 2001) for a particular audience, then that status changes. Online readers become ratified participants in the metadiscussion that is primed by the particular framing of the news event.

While they might be ratified in terms of their new role as a meta-recipient (Kádár and Haugh 2013), they remain unratified as a participant in the original talk. Kádár and Haugh (2013) characterize this engagement in the metaworld as 'vicarious participation'. This is a useful term because it nicely distinguishes the metalayer of reportage and commentary from the field of action, yet also captures the investment of imagined participation. These interactants have a purpose in creating and posting comments; their actions serve to further mediatize the original event. In some cases, this involves a construal of the video sequence as entertainment: Soto is someone merely to be laughed at (see examples 21, 23, 24 in section 5, which display elements of this). But in the majority, Soto's behaviour is the focus. These comments function as a way of indexing, structuring and reinforcing presumed moral orders (Garfinkel 1967; Haugh 2013; Kádár and Haugh 2013) that are thus implicitly presented as the basis for proper social conduct. To an extent, this is no different from co-participant metapragmatic behaviour, which also has this ideological function. However, for those engaged as co-participants in the social field, ideological concerns have to be intertwined with the individual's management of their own face and identity practices within that particular interaction - their metadiscursive comments may be shaped by competing goals. Therefore, while these data lack insights 
into the ongoing discursive construction of politeness in talk-in-interaction, they are a rich source of (relatively) unadulterated evaluative behaviours by metaparticipants who choose to engage and do so largely for the purpose of social comment. ${ }^{2}$

In Eelen's (2001) characterization of the different orders of politeness, all lay metapragmatic behaviour was confined to first order politeness - broadly speaking, the dividing line between the two concepts lay in the distinction between lay and scientific approaches. Kádár and Haugh (2013: 87) argue that the reality is more complex - that lay metapragmatic behaviour has a place in both. For them, the distinction is between those who comment on talk in which they view themselves as participants (either as a ratified participant in Goffman's sense or as a metaparticipant) or those who observe talk (either lay or analyst) and characterize it in systematic terms. Thus, scientific theorizing and folklinguistic theorizing both count as second order politeness. This is an insight that has been a long time coming in (im)politeness research. It has long since been acknowledged in sociolinguistics in the context of the standard language debate (e.g., Niedzielski and Preston 2003) that lay members of a society have a structured understanding of the relationship between standard language and dialects - it is just that their theoretical position is rather different to that held by most linguists. Kádár and Haugh's insight is important because it recognizes and properly values the underlying systematicity to lay analyses of (im)politeness. Without this understanding, we are unlikely to identify the broader social orders that shape the social practice of which (im)politeness behaviour is a part.

In addition, in acknowledging that (im)politeness evaluations have an underlying systematicity, Kádár and Haugh (2013) have created an epistemological space within (im)politeness research for a lay, structured understanding of the interpersonal aspects of social practice. Although this is not discussed within their work (Haugh 2013; Kádár and Haugh 2013), it seems that this unfilled theoretical space fits nicely with the Garfinkelian concept of the 'moral order' that they use to explicate (im)politeness behaviours. Of course, Garfinkel's (1967) conception of the moral order encompasses more than (im)politeness

2 This is not to say that there are no face issues here. The poster is laying claims to very particular social positions so it is certainly a presentation of self (arguably, this is its key purpose from the poster's perspective). However, unlike co-present synchronous talk, the commenter does not need to take into account potentially conflicting face needs of others in the same way. Those considering responding to online discussions have a choice about whether to engage or not - if they perceive there to be potential face management issues they can decide not to post. In contrast, someone engaged in a face-to-face context often does not have that luxury. 
behaviours but, as we shall see, evaluations of (im)politeness behaviours are not restricted to indexing social meanings about (im)politeness. The interactions of meanings within social practice are not so easy to disentangle: folklinguistic theories of (im)politeness are always going to be enmeshed within broader lay social understandings of social practice. Thus when the concept of the moral order is invoked as part of the analytical process in this article, I am equally invoking a second order folklinguistic theoretical perspective on (im)politeness behaviour.

However, one issue does remain with Kádár and Haugh's (2013) argument that metapragmatic behaviour has a place in both first order and second order (im)politeness. This is the question of what means we can use to classify (an aspect of) a specific behaviour on a particular occasion in terms of these two categories. It is clear that invoking the idea of participation to differentiate them would be insufficient. As Kádár and Haugh (2013: 84-85) recognize, we can all be both participants and observers in the self-same interaction. Thus, the question remains of what particular behaviours count as involvement in the evaluative moment (first order) as compared to observationally-based theorizing about folklinguistic systems (second order). Another important issue is whether these can be achieved simultaneously. In terms of identifying both what counts as evaluative, metapragmatic behaviour and what that behaviour can tell us about (im)politeness and the moral order, this is an important distinction and key to developing robust ways of judging the validity of evidence for particular analyses.

As I will show in this research, there is a difference between classifying behaviour as (im)polite (or (in)appropriate), making assessments about people and providing evidence for beliefs about the moral order. These could all be seen as 'evaluations' but they do not have the same kinds of ideological weight or tell us the same things. Understanding this is critical to teasing apart the relationship between types of metapragmatic behaviour and the validation for analyses it can offer. This is brought into sharp relief in these data because although explicit classifications of behaviour as being (im)polite are rare, there are other discursive moves indicating an extremely high level of agreement that Soto's actions in the courtroom were considered 'inappropriate'. So the simplistic idea of evaluation being framed in terms of classifications of (im)politeness or even (in)appropriateness would not provide an insightful analysis. However, it is also evident that there is a discursive struggle concerning judgments of Soto's person and the rationales used to support these. An effective analysis of evaluation and metapragmatic behaviour needs to access these, and differentiate them from classificatory behaviour - this is still evaluation but it is of a different type. 
My thesis in this research is that it is through these rationales that we will gain the greatest insights into the differing conceptions of the moral order and that it is these that constitute evidence for second order lay theorizing about (im)politeness. It is in these rationales that we see what Eelen (2001) identified as argumentativity - the social positioning and indexing that is achieved through evaluation. While the concept of evaluation has been taken up widely within (im)politeness research, its partnering concept has been largely left behind, perhaps because it was left rather undertheorized. This is a pity because in Eelen's model, the locus of social struggle - the ideological element - appears to be in the concept of argumentativity not evaluation per se. The purpose of this article is to show why we need to recognize argumentativity as the key part of evaluative metapragmatic behaviour, and how doing so can sharpen up our understanding of the different elements of evaluation and provide better warrants for validating our use of metapragmatic behaviour in (im)politeness analyses. This will involve developing and operationalizing Eelen's concept of argumentativity before demonstrating how it can be used to show the mobilization of (im)politeness judgments as a resource for structuring and perpetuating understandings of moral orders.

\section{Habitus, historicity and argumentativity}

Eelen's concept of argumentativity is dependent on Bourdieu's concept of habitus (Eelen 2001). This is concerned with how previous social experiences help shape our social actions in future, and, in particular, why there are relative similarities in the reaction of individuals when presented with a new context: "all of my thinking started from this point: how can behaviour be regulated without being the product of obedience to rules?” (Bourdieu 1994 in Maton 2012: 50). A person's habitus is the result of all their previous social involvement, reflecting their unique set of experiences and interactions (historicity); it is in a process of continual evolution as a result of ongoing engagement with social practice. While past experience does not determine an individual's actions in a particular context, Eelen (2001: 222, original emphasis) argues that "[p]resent action is the creative transformation of present conditions from a position based in past experience”, thus allowing a mediating position between (the constraints of) structure and (the autonomy of) agency. While Bourdieu focuses on the relative commonality of social experiences within a particular cultural milieu, thus enabling the potential for a degree of predictability in the response to a particular social configuration, Eelen highlights the reverse 
perspective: habitus does not only account for a relative degree of self-regulation in human behaviour, it also allows for variability. Many social experiences may be shared but each individual will have a unique cultural and social trajectory thus allowing for the combination of past experience and current involvement to generate a range of different responses. It is this, Eelen argues, that accounts for the variation in first order politeness - in both (im)politeness in action and metapragmatic behaviour. ${ }^{3}$

Such social variation results in argumentativity: differences in social actions are not socially - and thus, ideologically - neutral. Choosing to employ a particular configuration of linguistic elements positions the speaker in relation to the options that are - and are not - selected. Evaluating another's behaviour by classifying it as polite/impolite or engaging in metadiscourse about (im)politeness has a social aim and social effects (Bourdieu 1991; Eelen 2001). The difference between variation and the argumentativity that comes from evaluation seems to be that these invested classifications are used as a resource for social meaning - to index particular discursive positions. They are not 'neutral' scientific classifications, like biological taxonomies such as the classifications of insects. To illustrate this distinction, Eelen uses the example from the Nazi era of the ideologically-loaded classification of humans into Untermenschen and Übermenschen as a different categorization system that had ideological effects in the structuring of beliefs in a society.

However, Eelen does not give a precise definition of argumentativity as such. Initially, it is defined in a footnote: "[it] will be used in a loosely descriptive sense, referring to various forms of 'involvedness' or 'interestedness'." (Eelen 2001: 37). It's meaning is only addressed further one more time in the book's penultimate chapter. Here, the argumentativity of (im)politeness behaviour (arising from variation) is seen as a "social tool of identification and distinction" (2001: 224), which is used to actively index information about the social world. Neither of these moments work to specify the precise role of argumentativity - the first being rather vague and the second trying to define argumentativity in terms of politeness behaviour (which seems to be confusing the role of explanandum and explanans). I would argue that this is a crucial omission in Eelen's work, and may explain why this concept has not been taken up with the same enthusiasm as the concept of evaluation. What we need is to go back to the relationship between structure and agency: the structuring effect of classification (or the particular (im)politeness choices made) is not in the process of classification (or doing being (im)polite) itself but in the rationale

3 And by extension to lay theorizing about (im)politeness - thus crossing the boundary into second order (im)politeness. 
that underlies those decisions. If I classify behaviour as 'impolite', it is my rationale for doing so that shows how I think society should be ordered, it is not the classification in itself. If I produce some politeness-in-action, it is the reason that I chose that particular configuration of phenomena that offers the insight into my conception of the moral order. The argumentative link between (im)politeness behaviour/metapragmatic behaviour and some underlying conception of the moral order is their rationales.

For example in Haugh (2013: 58-59), Lisa constructs a complainable about an acquaintance, Edna, whom she negatively evaluates due to Edna's behaviour when Lisa gave her a lift to church the previous week:

15 Lisa: So I don't wanna, - (1.2) I don't wanna

16 pick up Edna for chu:rch. (hh)

$17 \quad(1.1)$

18 Bob: Pick up who?

$19(0.7)$

20 Lisa: Edna: .

21 Tom: E[ dna:?] (.) Where does she live?

22 Bob: [ mmm. ]

$23(0.6)$

24 Lisa: On Anzac Avenue. but- (.) she just, - (1.2)

25 like last week she made me take her home

26 straightaway after the service. (0.4) so

27 I had to leave and then (0.7) c [ome back. ]

28 Bob: [Come back.]

$29 \quad(0.7)$

30 Tom: Oh

31 Lisa: And just-she's just re:ally, (.)

32 doesn't think of anyone but herself.

$33(2.1)$

34 Tom: Is she a youth student?

$35(0.5)$

36 Lisa: $\mathrm{No}=$

37 Bob: $=$ No: she's $^{\circ}{ }^{\circ}$ friend from school.

$38 \quad(0.4)$

39 Lisa: School friend.

40 Tom: $\uparrow \mathrm{O}: \mathrm{h}(\mathrm{h}) \circ(\mathrm{hh}) \mathrm{k}$.

4 Transcription conventions and line numbers have been preserved from the original text. 


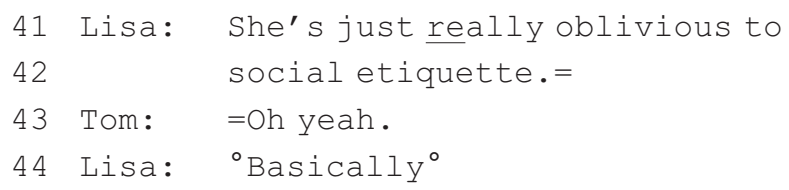

In lines 25-27, it can be inferred that Lisa felt Edna's behaviour was not appropriate to a lift recipient. By the use of made and had to, it is clear that Lisa is framing the extra trip as being obliged to do something against her will. At no point does Lisa explicitly classify Edna's behaviour as (im)polite but there is an implicature (Grice 1975) that she evaluated her behaviour negatively; this is reinforced by the initial framing in lines 15-16 that Lisa did not want to repeat the experience. However, this negative assessment does not give an insight into how Lisa believes Edna has violated the expectations of her role as lift recipient and thus how it has disrupted the moral order. This only comes in lines 31-32 and 41-42, where 'thinking of others' and 'etiquette' is given social value, and thus connected to broader ideologies about what is important in the negotiation of social behaviour. And it is this connection between evaluation and the social order that is socially argumentative and provides the rationale.

While Haugh does recognize the relevance of the reference to 'thinking of others' and 'etiquette' to the moral order, he does not (explicitly) highlight it in his analysis in respect to other types of evaluative activity. This is partly because he is also focused on the interactional emergence of the evaluative moment as negotiated by all the participants. However, this lack of attention to the heterogeneity within evaluative behaviour is also more generally a feature of (im)politeness analyses: we recognize classifications, positive/negative assessments and rationales all as forms of metapragmatic, evaluative behaviour (which they are) but we do not particularly distinguish them and we do not give precedence to the argumentativity - the rationale. I can recognize this in my own work (e.g., Davies 2011), though perhaps as a critical discourse analyst I rather take this link for granted. Many shifts in theoretical thinking are about recognizing and articulating the obvious (but unstated) in what we already do. But these are still important because they can enable us to refine our understandings.

Thus, I would argue that it is important to unpack the different aspects of classificatory, assessing and argumentative elements from (im)politeness metapragmatic behaviour. Each are important aspects of (im)politeness metadiscourse but they each indicate a different level of social meaning and they are also independent of each other. For example, we cannot equate the classification of behaviour as 'polite' with a positive assessment of that person or, con- 
versely, that 'impolite' behaviour means a negative assessment. It is true that the relationship between these two often does pattern in that way but it is far from monolithic: for example, it is possible for 'polite' behaviour to be negatively assessed because it is viewed as artifice (Deutschmann 2003). Equally, a negative assessment in itself does not reveal why the speaker has evaluated it in that way - it does not provide the argumentative link to their construction of the moral order.

To explicate this further, Table 1 uses constructed examples to show the different types of relationships between classification, assessment and argumentativity, and what we can take them to mean in terms of the idea of an underlying moral order.

It is important to clarify that there is space for inferencing by the analyst in this model but there are much stronger justifications for top-down inferencing (e.g., rationale to assessment) than for bottom-up inferencing (e.g., classification to assessment). For example, if I say 'He's far too smooth and smarmy' (Assessment, Table 1), I am fairly explicitly offering a negative assessment of the person to whom I am referring. My addressee can probably also infer that I think there is something problematic about that person's behaviour - it is inappropriate or impolite in some respect. Thus the classification is largely inferable from the assessment. However, it would be harder for an addressee to understand my rationale for making this assessment - at least, on the basis of this evidence alone. They might invoke societal ideas about politeness as a form of artifice and generate weak implicatures on this basis, but these could only offer limited evidence for my understandings of the moral order. More evidence - in the form of additional contributions to the ongoing discourse or elements of a shared discursive history - would be needed to give deeper insights into those understandings. Therefore, the rationale is not (easily) available from the assessment.

Indeed, even such top-down inferences may not always be accessible: these might need further evidence to be interpretable. If I say 'You can always tell when someone's been to a private school' (Assessment, Table 1), it is not selfevident in the UK context whether I am making a positive or negative assessment. In order to access that judgement, one would either need further discursive evidence in the progression of the talk (e.g., comment that gives insight into the assessment) or personal knowledge about the speaker's attitude to private education and those who have been educated in that way. Thus, we always have to be careful to substantiate the basis for the evidence we claim and the degree of certainty we can allow our interpretation. This is particularly key when we are acting as linguist observers and do not have a shared personal 


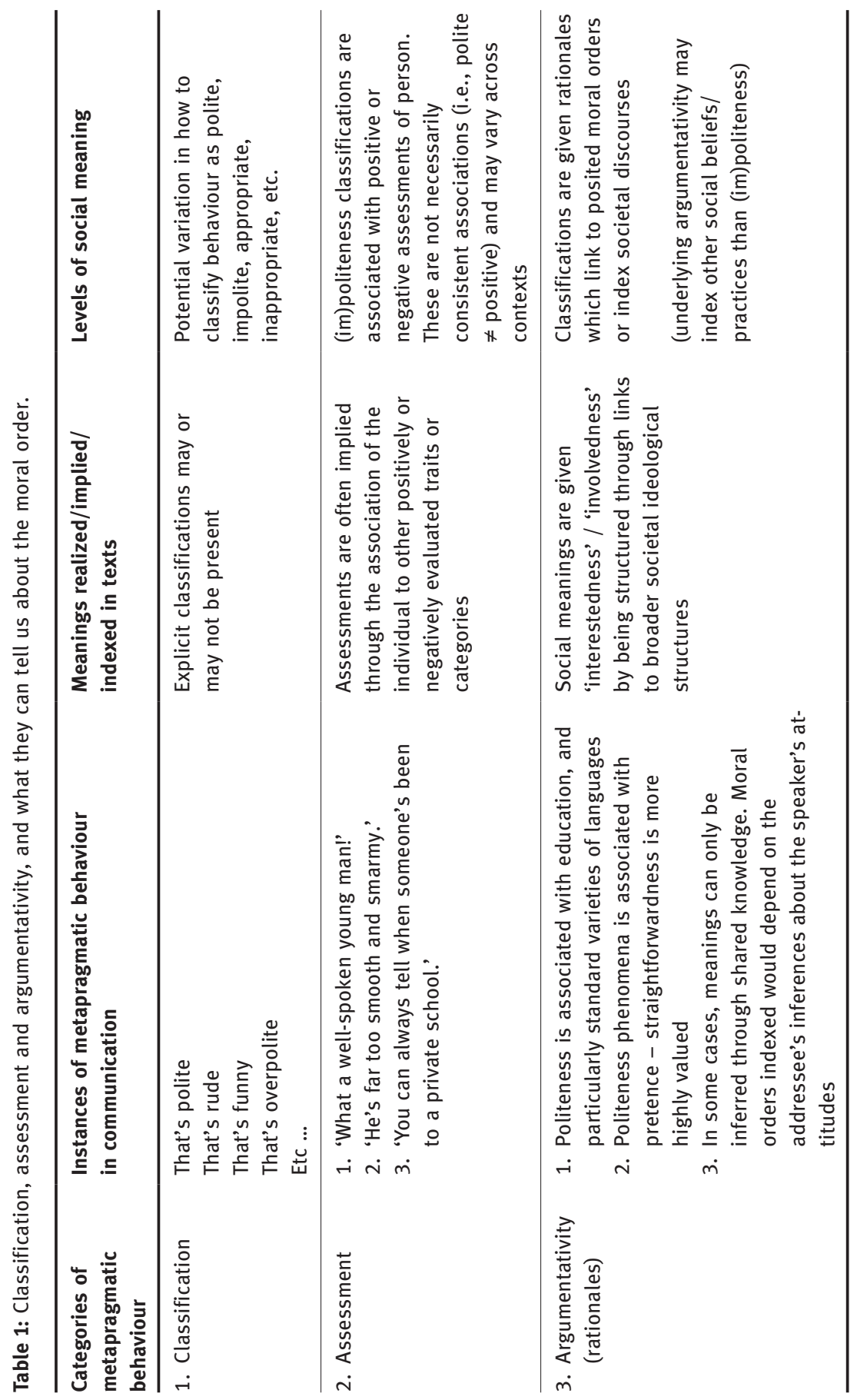


history with interactants - such understandings may be discursively constructed over time and may not be directly evidenced in the talk at hand. ${ }^{5}$

It should also be noted that there is no requirement in this model for argumentativity to emerge discursively: a stand-alone comment on an online newspaper article, in a tweet or in a Facebook status has the potential to produce ideologically-loaded social meanings through the positioning of social behaviour as (im)polite. As discussed in Section 2, evaluation through both talkin-interaction and metaparticipation are both valid sources for metapragmatic analysis.

Argumentativity is preferred here to contested because although the latter is associated with the lexis of discursive struggle, it does not distinguish between differences in assessment (positive vs. negative) as compared to differences in rationale (differences in the structure of the posited moral order). As we will see, it is entirely possible for agents to agree on the assessment of a behaviour as positive or negative (i.e., it is not explicitly contested), but disagree on the reasons why it should be categorized in that way (i.e., it has a different argumentative structure). And if we are interested in the 'discursive struggle' over politeness - and thus over what constitutes the 'moral order' - then we need to focus on argumentativity rather than classification or assessment because this is where the work of structuring social meaning is achieved.

\section{Data and methodology}

The primary data for this article consist of 338 unique user-generated belowthe-line comments ${ }^{6}$ from three Daily Mail articles that covered the Penelope Soto story. These articles were published over a period of one month, and each deals with a different interaction that Soto had within the US court system. It was decided to use data from all three because firstly, the comments often referred back to the original story and secondly, it was insightful to see whether assessments of Soto's behaviour changed and how these assessments were justified in terms of their rationale.

The first courtroom interaction involves a bail hearing for a charge of illegally possessing a prescription drug. Soto is a first time offender, and has not

5 Though such understandings are also not necessarily available to all those engaged in talk, either. Engagement in itself does not guarantee that one has access to all relevant shared understandings.

6 Duplicate comments and those that made comments not relevant to this study (e.g. sexualized comments about Soto's appearance) were excluded. 
previously experienced court. The purpose of the hearing is to assess whether Soto should be allowed bail, what the surety for bail would be, and whether or not she qualifies for free access to a defense attorney. Defendants stand in line in a room separate from the court, connected only by a video link. They are waiting their turn to be processed: these are routine encounters for a circuit courtroom, which take only a few minutes each.

The initial courtroom interaction involving Soto can be divided into three phases. In the first phase, Judge Rodriguez-Chomat tries to establish Soto's suitability for bail and whether she has sufficient funds to appoint her own defense attorney. This includes a discussion of Soto's assets, including her claim to own jewellery. When the judge has completed his questioning, she is assessed as not requiring a state defense attorney and a $\$ 5000$ bail bond is set. The setting of these terms concludes the normal business of the court hearing and this phase of the interaction is completed by the judge dismissing Soto by saying 'Bye bye', to which Soto responds 'Adios'. She then leaves the front of the queue and starts to move away, presumably to an exit that is out of sight of the video link. It is this exchange that seems to be a turning point in the interaction. In the second phase, the judge calls Soto back and increases the bail bond to $\$ 10,000$. He dismisses her for a second time, echoing her previous use of 'Adios'. In response, Soto 'flips the bird' (a rude hand gesture) and swears at the judge as she turns away. In the final phase, the judge recalls Soto again and asks her whether she swore, an action that she immediately acknowledges. The judge finds her in contempt of court and sentences her to 30 days in the county jail. Soto responds with 'That's fine' and turns away for the final time. This completes the interaction.

What should have been an unremarkable encounter in the life of the courtroom had gone badly wrong, having extreme consequences for one of its protagonists. The issue taken up by both the media and their audience was why and how this had happened: who was to blame? The Daily Mail reportage and responses were no exception to this.

The Daily Mail is a British mid-market tabloid paper with a right wing, conservative stance. It is one of the most popular newspapers in the UK with a print circulation of approximately 1.5 million (July, 2016, www.newsworks.org.uk/ Daily-Mail) and an overall reach via all platforms of nearly 30 million monthly. It also has a very strong international presence. MailOnline is the most visited English language website in the world and it has separate homepages for the UK, USA, India and Australia (Mance 2014). Nearly $70 \%$ of its website traffic is from users outside the UK, and the USA is particularly highly represented (Sweney 2014). Indeed, for this USA-based story, a large percentage of the comments were posted by users stating their place of residence to be the USA. It 
Table 2: Articles from The Daily Mail relating to Penelope Soto.

\begin{tabular}{|c|c|c|c|c|}
\hline Date & Headline & Topic & $\begin{array}{l}\text { No. of } \\
\text { comments }\end{array}$ & Code \\
\hline 05.02 .2013 & $\begin{array}{l}\text { Are you serious? The moment } \\
\text { female thief flips out at judge ... } \\
\text { and gets jailed for THIRTY DAYS } \\
\text { as punishment (Reilly 2013a) }\end{array}$ & Bail hearing & 187 & BAIL \\
\hline 09.02 .2013 & $\begin{array}{l}\text { Teenage girl who got } 30 \text {-day jail } \\
\text { sentence for flipping off a judge } \\
\text { gets released after tearful } \\
\text { apology (Reilly 2013b) }\end{array}$ & $\begin{array}{l}\text { Soto apologizes } \\
\text { to Judge } \\
\text { Rodriguez- } \\
\text { Chomat; released } \\
\text { from jail }\end{array}$ & 90 & APOL \\
\hline 02.03 .2013 & $\begin{array}{l}\text { She cleans up well! Girl who } \\
\text { flipped off Miami judge shows up } \\
\text { in court looking prim and earns } \\
\text { APPLAUSE for change in attitude } \\
\text { (Daily Mail Reporter 2013) }\end{array}$ & $\begin{array}{l}\text { Arraignment } \\
\text { hearing }\end{array}$ & 61 & ARRAIGN \\
\hline
\end{tabular}

was chosen for this research because of its relatively large audience and also its strong presence in the USA.

Like many bulletin board systems, the Daily Mail comments section lists postings in reverse chronological order (the most recent ones are at the top) and there is no mechanism through which to create a 'thread'. This kind of system tends to discourage the development of discussion as the user is reading against the temporal discursive structure (Wright and Street 2007; Davies et al. 2011) and the user would have to use explicit addressivity (Herring 2001) to signal that a post was intended as a response to another. There are occasions where this does happen in these data but none of these conversations takes up (im)politeness as their theme. Therefore, they will not be considered here. Instead, we will be treating these postings as 'one-shot' metacomments on Penelope Soto's courtroom interactions.

The user-generated comments were analyzed in terms of any (im)politeness terminology used (polite, impolite, rude, respect, manners, etc.). They were categorized according to whether they assessed Soto's behaviour negatively or positively, whether they categorized Soto herself negatively, positively or neutrally and whether they categorized the judge's behaviour as negative or positive (neutral assessments did not occur). Sometimes there was explicit evidence for these judgements, in other cases an inference had to be drawn based on rationales given and the broader discourses indexed. However, on occasion, the possible inferences were ambiguous and these examples were left unclassified (as 
in example 28, discussed in section 6). Finally, each comment was analyzed in terms of the rationales given for the categorizations.

In the context of this article, the focus will be on close, qualitative analysis of representative examples. However, these are drawn from an analysis database that records a thorough dissection of each of these $300+$ short texts. Therefore quantitative information is provided where it can give a greater indication of the landscape that a textual example inhabits. In the analysis that follows, initial attention will be paid to classification and assessment of (im)politeness behaviours in the texts before moving on to explore the argumentative rationales underlying these aspects of the evaluations.

\section{Analysis}

The starting place for this analysis is the fact that there is near-universal agreement from the posters that what Soto says and does in the initial courtroom interaction is inappropriate. So there is not much variation here in the basic classification of the behaviour as socially appropriate or problematic. However, there were four comments (1\% overall) where Soto's behaviour was evaluated non-negatively. Two examples of this are given below to show the kinds of rationales that were given in this context.

\section{(2) ${ }^{7}$ drago42, USA}

She shouldn't have to apologize. The judge is a crackpot and a bully. She did nothing wrong. Absolutely nothing. He deserved to be flipped off. It's ok, most people apologize but don't mean it in the legal system. There are so many ridiculous laws that people "break" and get caught for, that didn't hurt anyone. The cops and legal professionals that enforce them are some of the saddest, dumbest people on Earth. [APOL18]

(3) Armand Ippolito, USA

ohhhh please, cut the fake sympathy and congratulations. I wish she would have stayed true to herself and flipped off the new Judge! FARK THE MAN!!!!!! /and yeah, i'd hit it! [ARRAIGN 63]

Example 2 is the only one in the data that clearly classifies Soto's behaviour in the first phase of the interaction (up to the 'Bye bye' - 'Adios' exchange) as

7 All examples are reproduced as posted with any original typographical errors. The code BAIL, APOL, ARRAIGN are used to identify the article that was being commented on and the number represents its position in chronological sequence, from first to last. 
socially appropriate. It is more ambiguous on Soto's swearing and gesture the use of deserve may suggest that her behaviour at this point would not normally be considered appropriate but it at least positions her reaction as justifiable in the context, using a negative evaluation of the judge as the rationale. The argumentative move here is to link this individual judge's perceived failure to perceived failures in the justice system as a whole. In contrast, example 3 does not seem to assess Soto's behaviour as within societal norms but does positively align itself with her by rejecting the validity of the basis for those norms. This is clearly argumentative social behaviour because it is promoting an alternative social order in which alternative social norms would hold.

While these examples show that agreements in assessment of Soto's behaviour were not monolithic, the quantitative picture shows a very high degree of consensus. However, this is still interesting data from the perspective of (im)politeness even though the classifications of the behaviour as appropriate or not have clustered so neatly. The variability lies in whether Soto herself is evaluated positively or negatively and how this is argumentatively constructed using rationales about her linguistic pragmatic behaviour and other social practices. To get at the way in which social orders are constructed and contested, we have to move beyond merely the metapragmatic classifications of (im)politeness.

In these data, the key area of disagreement centered around the relationship between the classification of the behaviour (positive/negative) and the assessment of the person (good/bad). While most agreed the behaviour was problematic, there was not such a consensus over whether such inappropriate behaviour should be taken to index 'bad personhood' or not. However, by far the most typical response from posters was to equate behaviour and person and thus negatively evaluate both. This is perhaps not unsurprising given the conservative, right wing political stance of The Daily Mail and thus its selfselected readership.

(4) DVM, USA

GOOD FOR THE JUDGE! What a stupid, giggling idiot that girl is. Yes, she has the right to freedom of speech and expression, but that comes with the responsibility for the consequences of that freedom. Dis the judge, take what the judge dishes out. Hope the little fool does some serious thinking in jail and straightens out her life. [APOL 29]

$81 \%$ of the comments involved explicit negative assessments of Soto, and these often equate her negatively assessed behaviour with a bad inner self. In exam- 
ple 4, she is given absolute agency - it is constructed as a knowing and intentional presentation of self - and that this bad inner self is enduring: she needs to 'straighten out her life'. Many of these involve positive assessments of the judge, made either explicitly (21\%), as above, or implicitly (a further 66\%). However, there was also a significant minority (7.4\%) who classified Soto's behaviour as inappropriate but were unwilling to ascribe her an impolite intention. They often cited her inexperience of the courtroom context and also the behaviour of the judge.

(5) Will, USA

This is ridiculous. Watch her body language. Seems more like she was uncomfortable discussing the value of her jewelry, causing nervous laughter. And then he says "bye bye", so she says "adios" with a smile, thinking she's being polite. The girls only 18 , why is this whole country crucifying her? [BAIL 210]

(6) Stevoid, UK

This man should have realised he was dealing with someone with either under the influence of drugs, or had mental health issues. He DID seem to be provocative, and did engage her in the familiar - and familiarising vernacular of her age/environment. She walked right into it with the adios comment that seemed to enrage him. We might not like it, but we expect our judges to demonstrate insight and restraint, forethought and wisdom ... which is why we pay them so much. This was lacking in this case .... makes me wonder if the state animal on the flag behind him shouldn't be changed to a Kangaroo [BAIL 222]

Both examples 5 and 6 position Soto as an incompetent participant, either through inexperience and nervousness or through an incapacity caused by drugs or mental health issues. This implies at least a non-negative assessment of Soto as a person (if not a positive one) as a non-competent person cannot be held entirely responsible for their behaviour. ${ }^{8}$ To use a concept from Goffman (1967: 45), Soto is constructed as not being a 'usable participant'. This contrasts absolutely with the previous example where the use of 'responsible' and 'freedom' position Soto as being at liberty to choose her course of action, thus making the negative outcome a direct result of her agency. The argumentativity of

8 These are non-negative judgements in terms of an assessment of 'good' vs. 'bad' personhood. However, these are certainly face-damaging statements for Soto since she is being positioned as a non-competent member. 
intent is latent in many of these posts but both examples 5 and 6 make a claim for a polite intent more explicit, particularly around the key moment of the 'Bye bye - Adios' exchange. In the former, this is constructed as 'thinking she's being polite' - clearly a reference to a polite intent - and in the latter as 'she walked right into it'. This metaphor of a trap being set for Soto is justified by the author both claiming that the discursive context is emergent and dynamic, and positioning the judge as having the major responsibility for the management of this - for which failure he is explicitly negatively assessed, thus releasing Soto from (the major part of) blame.

The argumentativity of intent is based around both its unknowability (and thus unchallengeability, see Hill 2007; Davies 2009) and whether or not an impolite intent is necessary to activate impoliteness. Terkourafi (2011) demonstrates that historically there has been little consistency in folklinguistic judgements about this, with much variation in both time and space. Politeness theorists are no more in agreement, with researchers such as Bousfield $(2008,2010)$ and Lakoff (1989) claiming such an intent is a requirement, Terkourafi (2008) claiming a distinction between impoliteness and rudeness on this basis and those such as Culpeper (2011), Locher and Watts (2008) and Holmes et al. (2008) claiming that impoliteness is a judgement made by the addressee, and thus that a perception of impoliteness is sufficient. This makes it a versatile resource for building broader social discourses. In this case, both sides claim knowledge of intentions but then use this to structure different understandings of social agency - to what extent someone in Soto's position can act autonomously or is constrained by the institutional context and roles of the courtroom. Those who position Soto as being buffeted by the court and the judge position her as being at the whim of institutional agency and thus not in control of her own destiny. Whereas the agentive Soto in example 4 becomes master of her own fate - and she can then stand as a marker/proxy for other perceived ills in society. This is apparent in the following three examples where Soto's perceived failures are mapped onto perceived failures of her generation and/or the parenting they received:

\section{(7) CM, USA}

Good. Today's youth seems to have a sense of entitlement and that they can act however they want with no reprecussions. Good to see a judge actually putting their foot down! [BAIL 22]

(8) India Andrews, USA

Every year I have students like her. It's sad how some parents fail to raise their kids. [BAIL 99] 
(9) ProfNickD, USA

There you go, the end result of single moms attempting to raise children. [APOL 80]

This is then linked to discourses about failures of parenting and/or family breakdown (examples 8 and 9). Such moral panics about the behaviour of young people have been present in society for a long period of time (Cohen 2011 [2002]), and are remade by each passing generation. ${ }^{9}$ The purpose of these postings seems to be not so much to evaluate Soto's behaviour as an instance of (im)politeness but to reinforce societal hegemonies: it is the argumentative link that can be made between Soto as an instance to the generic claims about societal problems. Indeed, in examples like (8) and (9), it is only these argumentative links that are stated: the assessment and classification processes have to be inferred from the generic claim that is made. It also demonstrates the argumentative nature of (im)politeness as a social tool: while as (im)politeness theorists, we may be most interested in what evaluation tells us about (im)politeness, it can also be used by speakers as a way of indexing other aspects of the moral order.

The issue of intention is also related to the contested concept of sincerity another resource for argumentativity in these data, as we will see in the examples below. Speakers' intentions in relation to sincerity (i.e., whether or not they mean what they say) are as unknowable as their intentions vis-à-vis (im)politeness. There is also disagreement regarding whether sincerity matters, particularly in regard to politeness acts or phenomena that do not commit the speaker to a future action whose absence would be noticeable (for example, an apology in comparison to a promise). In these cases is taking the responsibility for having the appropriate feelings (Searle 1969: 62), and thus greasing the social wheels, sufficient in itself? Or does their absence mean the attempt is hollow (Austin 1975) and therefore loses its polite illocution?

In her second appearance in court, Soto makes a tearful apology to Judge Rodriguez-Chomat where she claims to have been under the influence of drugs at the time of the bail hearing, thus providing an account for her claimed uncharacteristic behaviour. As a result, the 'contempt of court' charge is dropped and she is released from county jail. Again, there is disagreement on whether Soto should be assessed positively or negatively for her behaviour in this con-

9 Furedi (2015) claims the first mediatized moral panic relating to adolescent behaviour related to the rise of the novel in the $18^{\text {th }}$ century and the concomitant 'excessive reading'. Jane Austen's protagonist in Northanger Abbey, Catherine Morland, gives some credence to this. 
text. Largely, those who assess her negatively claim that her apology/presentation of self is insincere and is further evidence of her enduring bad self.

(10) Larry P., USA

She will be back. [APOL 2]

(11) kenzo, USA

3..2..1..Camera Roll....She's turning on the water works. She's a great actress. [APOL 53]

(12) jacka, USA

Punk, real outburst, fake apology, rotten outlook on life, justice system will see her again. [...] [APOL 64]

(13) Ruthie b., USA

She is not sorry. She will continue her lif of crime, I would bet. [APOL 102]

(14) Sharron, USA

This girl is trouble from the gitgo......nothing else to say. She only caved so as not do any more time....she's not foolin me. She will be in Court again....down the road....you can take that one to the bank. [APOL 109]

In some cases the negative evaluation is located (at least partially) in a linguistic categorization - 'fake apology', 'not sorry' - or by reference to perceived insincerity in other aspects of her practice - 'She's a great actress', 'she's not foolin' me' - but in others it is left implicit. 'She will be back' in example (10) can only be made relevant if the audience understands it as a judgement of a perceived mismatch between what Soto has said in this hearing and her inner self - only a 'bad' person will return to court, thus Soto's apology must be a faulty representation of her person. This move from negatively assessing Soto for a claimed lack of sincerity to categorizing her as a future jailbird relies on structuring an idea of the self where personhood is consistent: they are consistently good or consistently bad. Thus one instance of negatively assessed behaviour is sufficient to justify an enduring negative evaluation of that person. Hill (2007) discusses this idea of a 'consistent inner self' in relation to discourses of defense against racism, where the objective is to demonstrate a good inner self with which racist behaviour would be inconsistent. ${ }^{10}$ While the reverse

10 One key defense is the claim of a lack of intention (which is another interesting link to the present case) but the other is to provide evidence of the person's positive qualities - the inference being that to behave poorly (to be racist) would be inconsistent with this and therefore it is not tenable. 
seems to be true here, it is the consistency of selfhood that is important - in both cases it serves the ideological purpose of categorizing the person in the desired way. This is made more explicit in the following example:

(15) BobbyHuertas70, USA

Her good behavior is feigned and shall not last long. A tiger doesn't shed its stripes. A leopard doesn't change her spots. She's garbage now and will forever be. [ARRAIGN 4]

(16) elisabeth, USA

crocodile tears. [APOL 29]

(17) elisabeth, USA

Still wouldn't hire her. [ARRAIGN 30]

In example (15) alongside an explicit reference to insincerity, 'feigned', the poster invokes the biblical idiom 'a leopard doesn't change their spots' to evidence this assessment: since she has an enduring bad self, her seemingly good behaviour must be insincere. Whereas in examples (16) and (17) we see the same contributor maintaining their negative assessment - and the argumentative link to sincerity - across responses to both the Apology and the Arraignment newspaper articles. These individuals seem reluctant to entertain re-evaluating Soto's selfhood in the light of more evidence from social interactions. It seems that once they have made the link between inappropriate behaviour and a bad enduring self in this context, they are not prepared to make a re-assessment.

Of course, this argumentative move of exploiting the unknowability of sincerity also has an impact on the structuring of the ideologies that constitute folklinguistic theories of politeness. Sincerity is positioned as a key requirement to moral behaviour and successful personhood. However, this is not consistent across these data and it is particularly interesting to examine this issue in relation to the concept of 'respect', which is the most frequent politeness-type classification used in the comments. Contributions that invoke respect fall into two categories: those that assume the doing of respect should be sincere and those that see it as a common-sense requirement of the context (and thus sincerity is not a prerequisite).

(18) kye. K, UK

Serves her right too. Kids and teenagers are far too disrespectful to their elders now. They need to learn that their actions have consequences. [BAIL 10] 
(19) Incorrectly_Right, USA

Good for that judge, but unfortunately she will still probably be a disrespectful little...yea...after this. [BAIL 25]

(20) JustMyOpinion, USA

What a disrespectful brat no wonder she is in there.Good going for the judge. [BAIL 56]

(21) Art Vandalay, USA

Awww, and she's so cute! That must be why she never had to learn the meaning of "respect". HAHA! Cops and judges teach that lesson really well. Dang, though, she might lose her important job and expensive jewelry!! [BAIL 161]

(22) Pak31, USA

Obviously a girl who was raised without manners, respect for authority/ adults, etc. I love the fact that the judge didn't let her get away with her nasty attitude but I don't think releasing her early was a good idea. [...] [APOL 15]

The former of these categories is the more frequent, with $15 \%$ of BAIL hearing comments invoking 'respect' in such a way that it is seen as an intrinsic good and its lack is taken to index bad personhood. Examples (18)-(22) typify the tone of these. In example (20), Soto's perceived disrespect is a marker of an inner bad self, explaining her presence in the courtroom whereas in examples (19) and (22), she is assigned a 'nasty attitude' on the basis of her behaviour. This is again constructed as an enduring (bad) self by the use of 'still' (19), triggering an iterative presupposition (Levinson 1983). The failure to demonstrate respect is also seen as a failure of parenting (22) or of society more generally, as in example (18) (see also discussion of examples (7)-(9) above). Example (21) is interesting because alongside the invoking of 'respect', it implicitly criticizes Soto for another insincerity of self - this time in terms of a perceived exploitation of gendered behaviours. This is seen as a deliberate 'act' in order to avoid proper engagement with expected conventions, and thus another failure of self. ${ }^{11}$ Because respect is given such moral value in terms of selfhood in this set of comments, it can presumably only hold such value for these posters if its use is sincere. This would fit with the argumentative value of sincerity in the evaluations of politeness in examples (10)-(17) above. However, there is

11 I also note that the author of example (21) takes up the video of Soto as entertainment. This is frequent within the postings and also the mediatized event in general. It is an important aspect of mediatization and this form of 'mediatainment'. 
also a small minority of contributors who recognize the necessity for respect (either implicitly or explicitly) but construct it only as a social requirement that has to be fulfilled in order for the encounter to run smoothly for the less socially powerful participant, offering a different structuring of the moral order.

(23) Alexander -AC- H., USA

Haha what a dumbass. Don't you know you should never disrespect a judge? Especially the one who is in charge of your sentencing. [BAIL 21]

(24) Liz, USA

I loved the reaction of the people in the courtroom when she flipped the bird. Everybody there knew that was a dumb thing to do. Everybody except Miss Thang with the expensive bling! [BAIL 45]

(25) Flying J, USA

Rule Number One in the courtroom: don't p--- off the judge. [BAIL 108]

(26) JanSliver, USA

[...] This silly teenager was in possession of illegal prescriptions and she would have gotten away with a fine only if she shut her trap and respected the court. Instead, she took it as a joke and treated the judge in a manner that is considered contempt of court. [BAIL 192]

(27) dsgross309, USA

The judge handled that in a good way. [...] He explained to the "idiot" why it's not right or proper to treat authority in a crass manner. Look, we all know that authority can be wrong and horribly unjust but who doesn't understand -- when they control your life completely in the name of the law -- that you have to bow to your master. It's simple self preservation. [APOL 105]

The failure to produce what is evaluated as 'appropriate' behaviour is now constructed as a failure of logic or rationality rather than a moral failure. Soto is constructed as being stupid rather than irredeemably bad. She is a 'dumbass', is 'dumb', needed to 'shut her trap' to get away with it, and needed to make a rational judgement about the powers of the judge in the courtroom and behave accordingly: 'It's simple self preservation' (27). This is a critical difference in the way that these two groups of posters are constructing the moral order and the role of (im)politeness within it. An analysis of their classifications of her behaviour as (im)polite, or even an analysis of positive/negative assessments of her person, would not have revealed this difference. There's no question that the posters of both categories of comment negatively assess Soto's 
behaviour and classify it as being inappropriate. There is also no criticism of the judge in either set of posts. It is only by looking at the rationales behind these judgements that the argumentative role of (im)politeness in the structuring of the social and moral order becomes apparent.

\section{Discussion}

In this analysis, I have shown that the process of evaluation involves different components, not all of which may be explicit in the talk or text, and not all of which may be interpretable to the (linguist) observer. It is important to distinguish classification from assessment, and assessment from rationale, because each of these categories provides different levels of evidence about the folklinguistic beliefs held by the speaker/text producer. I have argued that the strongest level of evidence comes from understanding the rationale for an assessment and/or classification because this provides the argumentative link between the metapragmatic behaviour of classifying someone's politenessin-action as (im)polite and/or assessing them as a person because of (im)politeness behaviour: it drives those evaluative moments in talk.

It is argumentative (in Eelen's [2001] sense) because it is this ideological element that does the work of positioning both the speaker/producer and the evaluated in relation to a moral order posited by the speaker; it is this that makes it a 'social tool'. Each individual action also functions to structure and/ or reinforce societal views about moral orders - thus providing a link between the systematic understanding of the individual and the idea of societal norms and how they are created, maintained and change.

Classifications and assessments come from a speaker's understanding of the moral order, of course, but they only provide limited evidence of what precisely that might consist of. As an analyst, I might have hypotheses about the underlying reason for those judgements but without further evidence, such claims have to be regarded cautiously. One might use the metaphor of an iceberg - what is above the water gives only an indication of what lies beneath it, and what lies below may be much larger than what is visible. By identifying classificatory and assessing behaviour, we know that speakers are invoking a moral order but that may be all we know. This can be demonstrated from these data via an example that invokes the idea of 'respect' but had to be left uncategorized in terms of its rationale:

(28) Mike, USA

You must respect those judges. [BAIL 38] 
From looking at what is said and the discursive context in which it is said, it is clear that: (1) Soto's behaviour is classified as inappropriate; (2) She is being negatively assessed by the speaker. However, there is no accessible evidence through which a rationale can be reasonably or reliably ascribed. While I might make inferences as an analyst about what the contributor might be indexing by this - perhaps based on the popular view in these data of the necessity for sincerity, and the lack of evidence to the contrary - without more knowledge of that person, such inferences can only be quite weak. Therefore, I cannot access the full argumentativity of this evaluation because I lack context.

Even where rationales appear to be accessible, caution still needs to be applied and we need to provide evidence for interpretations. In the data analysis above, I have used concepts and theoretical positions very familiar from pragmatics (such as intention, sincerity, speech act theory, implicature, relevance and presuppositions) and other subdisciplines of linguistics (e.g., modality and lexis) as well as drawing on more critical discourse analytic concepts such as personalist ideology. In evaluative behaviour that emerges through talk, then an array of concepts from conversation analysis - such as markers of dispreferredness, turn-taking phenomena and adjacency - may become relevant. It is not what (linguistic) tools we use that matter but the fit between them and the type of language that we are analyzing, and their utility and robustness in providing insights into the ideological stances that underlie metapragmatic behaviour, and how those stances are taken up in talk. ${ }^{12}$

In these data, teasing apart the different elements that make up an evaluation allowed a more systematic analysis. I started with a few initial insights: there were few explicit classifications of (im)politeness (yet it was very clear Soto was disapproved of); 'respect' seemed to be an important concept; and certain contributors seemed very willing to seize on the potential for insincerity in the apology. However, it was only when I pursued a more quantitative approach - of independently categorizing the posts according to (implied) classifications, (implied) assessments of person and the type of discourses that were being invoked as support - that I could start to see the hierarchical relationships between these different layers and thus provide a richer analysis. For example, identifying 'respect' as a way of classifying (im)politeness behaviour was of limited utility because different contributors were using that same classification to invoke varying moral orders. Equally, identifying the issue of sincerity in the apology did not explain in itself why contributors felt justified in their continued negative view of Soto - finding the argumentative links made between bad behaviour and (enduring) bad personhood were essential to that.

12 See also Grainger (2011, 2013), who makes the argument that more traditional research in pragmatics and politeness still has a contribution to make to discursive analyses. 
Thus, what I have provided is a systematic way to identify different components in the evaluation process and to establish an orderly and robust way in which to seek meaningful links between them.

Distinguishing different, ordered levels within the process of evaluation may also be helpful in elaborating Kádár and Haugh's (2013) position that evaluation can be considered as part of both first order and second order politeness. They make the argument that lay observers are as capable of theorizing about language as linguists (although the kind of model produced might be rather different). What they do not do is explain how we should differentiate between first order and second order metapragmatic behaviour. However, separating evaluative behaviour into categorizations, assessments and rationales should allow us to do exactly that.

(29) jacka, USA

Punk, real outburst, fake apology, rotten outlook on life, justice system will see her again. [...] [APOL 64]

In the example above, there are classifications of Soto's behaviour ('real outburst', 'fake apology'), and there are also negative assessments of her person ('punk', 'rotten outlook on life'). These are tied to Soto, and tied to the moment of vicarious participation. Thus, these would seem to be instances of first order politeness. They are 'politeness-in-action', once removed. However, the rationales that underlie these judgements are theorizations about the moral order of society and robust mechanisms for judging people: (1) sincerity is essential to proper behaviour, and (2) internal selves are consistent (personalist ideology). Therefore, previous bad behaviour means Soto can be judged to have bad intentions and accordingly be insincere. Thus, these rationales that give insights into speakers' perceptions of the moral order and how we assess people in relation to that moral order are second order behaviours. We might argue over whether the assessment of selfhood is within the realm of (im)politeness, rather than being a broader sociological consideration, but the two are argumentatively linked here.

\section{Conclusion}

In this paper, it has been demonstrated that it is possible to refine our comprehension of the evaluation process and thus make analyses of metapragmatic behaviour more robust and more straightforward to evidence. Identifying the three components of the evaluation process means that the analyst can make stronger claims regarding what weight of evidence each element can provide. 
With the enhanced role of metapragmatic behaviour in second and third wave impoliteness research (Culpeper 2011; Grainger 2013), sharpening our understanding of how evaluation functions has become increasingly important.

In order to achieve this, Eelen's concept of argumentativity has been elaborated and operationalized in order to provide a way to ground evaluative metapragmatic behaviour in the folklinguistic moral orders that shape its production. This, too, has been a useful endeavour because argumentativity had been left behind as evaluation was taken up, yet there was no replacement concept to illuminate the ideological locus of evaluative activity. Instead, the ideological role of evaluation was taken for granted but there was no differentiation in the ideological effects of different metapragmatic behaviour.

As a side effect of this process, we have also gained greater insight into the relationship between metapragmatic behaviour and the different orders of (im)politeness. Locating the lay theorization of (im)politeness behaviour in the element of rationale has acted to confirm Kádár and Haugh's (2013) position that metapragmatic behaviour should be recognized as occurring in both first order and second order (im)politeness. In addition, it has refined their stance by also identifying precisely which elements should be considered to be facets of first or second order (im)politeness.

Evaluation is thus presented as the intricate part of (im)politeness behaviour that it should be recognized as being. Therefore, it can be used more effectively to evidence the analytical process in contexts of both vicarious participation and talk-in-interaction.

\section{References}

Austin, John L. 1975. How to do things with words: the William James lectures delivered in 1955. J. O. Urmson \& Marina Sbisa (eds.) $2^{\text {nd }}$ edition. Oxford: Clarendon Press.

Bourdieu, Pierre. 1991. Language and symbolic power. Cambridge: Polity Press.

Bourdieu, Pierre. 1994 [1987]. In other words: Essays towards a reflexive sociology. Matthew Adamson (trans.). Cambridge: Polity. [Originally published as chose dites (Paris: Les Éditions de Minuit).]

Bousfield, Derek. 2008. Impoliteness in interaction. Amsterdam: John Benjamins.

Bousfield, Derek. 2010. Researching impoliteness and rudeness: issues and definitions. In Miriam A. Locher \& Sage L. Graham. (eds.) Interpersonal pragmatics, 101-134. Berlin: Mouton de Gruyter.

Cohen, Stanley. 2011 [2002]. Folk devils and moral panics: the creation of the mods and rockers. $3^{\text {rd }}$ edn. London: Routledge.

Culpeper, Jonathan. 2011. Impoliteness: Using language to cause offence. Cambridge: Cambridge University Press.

Daily Mail Reporter. 2013. She cleans up well! Girl who flipped off Miami judge shows up in court looking prim and earns APPLAUSE for change in attitude. Daily Mail 02.03.2013. 
Available at: www.dailymail.co.uk/news/article-2287238/Penelope-Soto-Girl-flippedMiami-judge-shows-court-looking-prim-earns-APPLAUSE-change-attitude.html (Accessed 07.08.2017).

Davies, Bethan L. 2009. Metadiscourses of race in the news: the Celebrity Big Brother row. In Sally Johnson \& Tommaso M. Milani (eds.) Language ideologies and media discourse, 162-181. London: Continuum.

Davies, Bethan L. 2011. Discursive histories, personalist ideology and judging intent: analysing the metalinguistic discussion of Tony Blair's 'slave trade apology'. In Linguistic Politeness Research Group (ed.) Discursive approaches to politeness, 189219. Berlin: Mouton de Gruyter.

Davies, Bethan L., Tommaso M. Milani \& Will Turner. 2011. Multilingual nation online?: Possibilities and constraints on the BBC Voices website. In Sheena Gardner \& Marilyn Martin-Jones (eds.) Multilingualism, discourse and ethnography, 197-216. New York: Routledge.

Deutschmann, Mats. 2003. Apologising in British English. Umeå, Sweden: Umeå University. Dynel, Marta. 2011. 'You talking to me?' The viewer as a ratified listener to film discourse. Journal of Pragmatics 43(6). 1628-44.

Eelen, Gino. 2001. A critique of politeness theories. Manchester: St Jerome Publishing. Furedi, Frank. 2015. The power of reading: From Socrates to Twitter. London: Bloomsbury. Garfinkel, Harold. 1967. Studies in ethnomethodology. Englewood Cliffs, NJ: Prentice-Hall. Goffman, Erving. 1967. Interaction ritual. New York: Pantheon.

Goffman, Erving. 1981. Forms of Talk. Philadelphia: University of Pennsylvania Press.

Grainger, Karen. 2011. 'First-order' and 'second-order' politeness: institutional and intercultural contexts. In Linguistic Politeness Research Group (ed.) Discursive Approaches to Politeness, 167-88. Berlin: Mouton de Gruyter.

Grainger, Karen. 2013. Of babies and bath water: Is there any place for Austin and Grice in interpersonal pragmatics? Journal of Pragmatics 58(1). 27-38.

Grice, H. Paul. 1975. Logic and conversation. In Peter Cole \& Jerry L. Morgan (eds.) Syntax and semantics Volume 3: Speech acts, 41-58. New York: Academic Press.

Harcup, Tony \& Deirdre O'Neill. 2001. What is news? Galtung and Ruge revisited. Journalism Studies 2(2). 261-280.

Haugh, Michael. 2013. (Im)politeness, social practice and the participation order. Journal of Pragmatics 58(1). 52-72.

Herring, Susan. 2001. Computer-mediated discourse. In Deborah Schiffrin, Deborah Tannen \& Heidi E. Hamilton (eds.) The handbook of discourse analysis, 612-634. Oxford: Blackwell.

Hill, Jane H. 2007. Crises of meaning: Personalist language ideology in US media discourse. In Sally Johnson \& Astrid Ensslin (eds.) Language in the media, 70-88. London: Continuum.

Holmes, Janet, Meredith Marra \& Stephanie Schnurr. 2008. Impoliteness and ethnicity: Maori and Pakeha discourse in New Zealand workplaces. Journal of Politeness Research 4(2). 193-219.

Kádár, Dániel \& Michael Haugh. 2013. Understanding politeness. Cambridge: Cambridge University Press.

Lakoff, Robin. 1989. The limits of politeness: Therapeutic and courtroom discourse. Multilingua 8(2-3). 101-129.

Levinson, Stephen C. 1983. Pragmatics. Cambridge: Cambridge University Press. 
Locher, Miriam \& Richard J. Watts. 2005. Politeness theory and relational work. Journal of Politeness Research 1(1). 9-33.

Locher, Miriam \& Richard J. Watts. 2008. Relational work and impoliteness: Negotiating norms of linguistic behaviour. In Derek Bousfield \& Miriam Locher (eds.) Impoliteness in language: Studies on its interplay with power in theory and practice, 77-99. Berlin: Mouton de Gruyter.

Mance, Henry. 2014. MailOnline and the next page for the sidebar of shame. Financial Times 24.09.2014. Available at: https://www.ft.com/content/cf2e53d2-425e-11e4-a9f400144feabdc0 (Accessed 07.08.2017).

Maton, Karl. 2012. Habitus. In Michael Grenfell (ed.) Pierre Bourdieu: Key Concepts, 2nd edn. 49-65. London: Routledge.

Niedzielski, Nancy A. \& Dennis R. Preston. 2003. Folk linguistics. Berlin/NewYork: Mouton de Gruyter.

Reilly, Jill. 2013a. Are you serious? The moment female thief flips out at judge ... and gets jailed for THIRTY DAYS as punishment. Daily Mail 05.02.2013. Available at: www.dailymail.co.uk/news/article-2273778/Penelope-Soto-arrested-possession-XanaxMoment-Miami-teen-thief-flips-judge.html (Accessed 07.08.2017).

Reilly, Jill. 2013b. 'Teenage girl who got 30-day jail sentence for flipping off a judge gets released after tearful apology’ Daily Mail 09.02.2013. Available at: www.dailymail.co.uk/news/article-2276114/Penelope-Soto-Teenage-girl-got-30-day-jailsentence-flipping-judge-gets-released-tearful-apology.html (Accessed 07.08.2017).

Searle, John R. 1969. Speech acts: An essay in the philosophy of language. Cambridge: Cambridge University Press.

Sweney, Mark. 2014. Mail Online to switch to .com domain name. The Guardian 27.01.2014. Available at: https://www.theguardian.com/media/2014/jan/27/mail-online-comdomain-name (Accessed 07.08.2017).

Terkourafi, Marina. 2008. Towards a unified theory of politeness, impoliteness and rudeness. In Derek Bousfield \& Miriam Locher (eds.) Impoliteness in language: Studies on its interplay with power in theory and practice, 45-74. Berlin: Mouton de Gruyter.

Terkourafi, Marina. 2011. From Politeness1 to Politeness2: Tracking norms of (im)politeness across time and space. Journal of Politeness Research 7(2). 159-185.

Wright, Scott \& John Street. 2007. Democracy, deliberation and design: the case of online discussion forums. New Media and Society 9(5). 849-869.

\section{Bionote}

\section{Bethan Davies}

Bethan Davies is a lecturer in Linguistics at the University of Leeds. Her main areas of research are linguistic (im)politeness, the pragmatics of Grice, metadiscourse in media discourse and the discourse of transport. She is co-editor of Discursive Approaches to Politeness (Mouton de Gruyter 2011), Situated Politeness (Continuum 2011) and Analyzing British English: Conceptual and Methodological Aspects of the 'Voices' Project (Routledge 2013). She has also published in Journal of Pragmatics, Journal of Sociolinguistics, Journal of Language and Politics, and Pragmatics. 